\title{
Causal Effects of Affordance Change on Communication Behavior: Empirical Evidence from Organizational and Leadership Social Media Use*
}

\author{
Alvin $\mathrm{Zhou}^{\dagger}$ \\ Annenberg School for Communication \\ University of Pennsylvania
}

Please cite as:

Zhou, A. (2021). Causal effects of affordance change on communication behavior: Empirical evidence from organizational and leadership social media use. Telematics and Informatics, 59, 101549. doi: 10.1016/j.tele.2020.101549

\begin{abstract}
This article provides empirical evidence for two hypotheses in the affordance literature. First, by leveraging a small affordance change - Twitter increasing its character limit from 140 to 280 on November 7, 2017, employing an instrumental variable approach, and examining 143,771 original tweets published by organizational and leadership accounts half a year before and after the intervention, we showed the direct causal relationship between affordances and communication behavior on digital media platforms. Second, by exploring what factors could explain the heterogeneity of causal effects, we showed that previous endogenous perceptions of communication constraint predicted later behavioral changes, despite the same exogenous intervention. These findings highlight the role of human agencies in the face of technological changes and provide empirical support for the affordance approach to information communication technologies (ICTs) as a reconciliation between technological determinism and social constructivism.
\end{abstract}

Keywords: Affordances, Digital Media, Communication Behavior, Causal Inference, Instrumental Variable, Twitter, Organizational Social Media Use

*Pre-print version of the article published in Telematics and Informatics doi: 10.1016/j.tele.2020.101549. The manuscript's previous version, only using data on organizational social media use, is uploaded as Version 1 in this preprint. I thank Kokil Jaidka, Yphtach Lelkes, Dylan Small, the editor, and anonymous reviewers for their valuable comments.

†Corresponding Author, alvinyxz@upenn.edu 


\section{Introduction}

Much literature on how digital technology influences human communication has focused on one central concept: affordances (e.g., Halpern \& Gibbs, 2013; Taipale, 2014). An affordance approach to digital media argues that interpersonal communication and computer-mediated communication differ in one significant way, that the latter requires inhuman objects to encode and decode messages through technical infrastructure and channels, and the characteristics of these technical infrastructures and channels afford and affect communication outcomes, including but not limited to the creation of media content, the management of organizational knowledge, and the emergence of social interactions (Park \& Yang, 2017; Sun, Wang, \& Jeyaraj, 2020; Treem \& Leonardi, 2013). This affordance approach provided a theoretical lens for scholars to characterize different action possibilities on mediated channels and understand human-computer interactions in newly developed information communication technologies (ICTs) (e.g., Evans, Pearce, Vitak, \& Treem, 2017; Kaptelinin \& Nardi, 2012; Shin, 2017; Sundar, 2008).

Underlying this stream of research, the assumption lies that communication behavior on digital media platforms, such as social networking sites (SNSs), is closely related to and directly affected by affordances of these platforms. However, if we examine our knowledge critically, it becomes obvious that we do not actually have strong, rigorous, and documented evidence on the direct relationship between digital media affordances and human communication behavior. For example, we still do not know the degree to which a change in affordances can affect communication behavior in a causal manner. Further, in contrast to strong theoretical arguments that human agency affects how information technologies are used for communicative purposes (e.g., Nagy \& Neff, 2015), we also lack empirical evidence on whether and how varying human perceptions affect digital media behavior.

This gap in the literature was indeed difficult to fill, because affordances in most cases stay the same across time on digital media platforms. In lab experiments, researchers can artificially change affordances but it threatens external validity. Most existing empirical research used a qualitative and comparative lens to study the effect of affordances on mediated communication (e.g., Fox \& Warber, 2015; Halpern \& Gibbs, 2013).

The current study tries to fill the knowledge gap by taking advantage of a recent event of affordance change to provide causal evidence on the relationship between affordances and communication behavior. Twitter, notorious for its restriction on text length, suddenly changed its character limit from 140 to 280 on November 7, 2017, which provided a great opportunity for causal identification on the effect of affordance change on communication behavior. Supplementing recent case studies on the event (e.g., Gligorić, Anderson, \& West, 2018, 2019, 2020; Jaidka, Zhou, \& Lelkes, 2019), we report statistical details on how the switch induces changes in content creation and underline the role of platform affordances in shaping user behavior in the digital world. Analyzing the exogenous intervention with an instrumental variable (IV) approach and using organizational settings (i.e., top organizations and leadership Twitter accounts) as the research context, we show how the change in affordances leads to various degrees of change in social media use, i.e., the use of language and interactive features on Twitter. Estimating user engagement level and perceptions of communication constraint with numeric proxies, we further explore what endogenous factors, if any, can explain the various degrees of behavioral change. The result highlights the role of human agency in the face of technological changes, and provides empirical augmentation to the affordance approach to ICTs as a reconciliation between techno- 
logical determinism and social constructivism.

The paper is structured as follows. First, we review affordance theory and its application in literature to provide background on how the theoretical framework has developed and evolved in empirical studies. By doing so, we highlight how scholarly knowledge has assumed the direct connection between affordances and digital communication behavior without explicitly evaluating it. In the review, we also touch upon the debate between technological determinism and social constructivism to illustrate the value of rigorously evaluating human agencies during affordance change. Then, we introduce the case of Twitter character limit change, detail the empirical strategy for causal identification, justify the research context of organizational social media use, and present numeric variables and their respective hypotheses. After presenting results on behavioral recognizing agencies from both developers and users - helps researchers understand ICTs in society at large. We also discuss new ways forward to quantitatively and computationally analyze the role of digital media affordances in computer-mediated communication.

\section{Literature Review}

\subsection{The Affordance Approach to Information Communication Technologies}

James J. Gibson developed the theory of affordances in the field of ecological psychology to characterize the interactionist view of perceptions and actions, the gist being that affordances emerge from interactions between inhuman objects and human actors and support certain behavior in the physical world (Gibson, 1979; Greeno, 1994). This affordance perspective has been media, and provided scholars a theoretical framework to investigate relationships between actors and objects in our online and offline lives (e.g., Faraj \& Azad, 2012; Lintern, 2000; Norman, 1988; Sundar, 2008).

Affordances, simply defined as action possibilities available in the environment, usually refer to properties of technology that enable and restrict users' certain digital behavior in the literature (Evans et al., 2017; McGrenere \& Ho, 2000).

In empirical studies, the affordance framework has proved to be quite useful for scholars to theorize digital behavior. For example, a series of work has been conducted to compare communication behavior on popular social networking sites (SNSs), and many of them attributed their findings to the different affordances provided by those platforms (Fox \& Holt, 2018). Oz, Zheng, and Chen (2018) compared user-generated political responses on Twitter and Facebook, and found that Twitter invited significantly more uncivil content from participants. They argued that Twitter's affordances, emphasizing weak-tie building and limiting post lengths, triggered more de-individuation compared to those on Facebook (Chen, 2011; Oz et al., 2018; Reicher, Spears, \& Postmes, 1995). Halpern and Gibbs (2013) conducted a similar study and compared online deliberation on Facebook versus on YouTube. They also situated their findings in affordance theory and identified two affordances - identifiability and networked information access - as the root cause that makes YouTube a lesser place for political expression.

Insights from these comparative studies, along with some critical and qualitative work

85 (e.g., Chan, 2018; McGuigan, 2019), have put affordances at the forefront of the ICTs literature and demonstrated how the affordance framework can contribute to theory building in digital media 
research (see more examples such as Fu \& Zhang, 2019; Jaidka, Guntuku, Buffone, Schwartz, \& Ungar, 2018; Kim, Chun, Kwak, \& Nam, 2014). However, if we examine the existing literature critically, it becomes clear that the direct link between affordances and communication behavior has not been carefully investigated. Most studies attributed their findings to different affordances across platforms, but we actually lack documented causal evidence that shows affordances can change communication behavior.

The examination of causality between affordances and communication behavior is indeed difficult, since most digital media platforms do not regularly change their affordances. Even when they do, their A/B testings are usually conducted and analyzed in house, without public data accessible for scholarly research. Some scholars tried to establish the causality using lab experiments, but many of them are comparative in nature and lack external validity (e.g., Oz et al., 2018). A few studies have taken advantage of a public event of affordance change - Twitter increasing its character limit from 140 to 280 - and provided some evidence on the link between al., 2018, 2019, 2020; Jaidka et al., 2019). The current study contributed to this growing trend of quantitative analyses of affordance theory by examining the same case but focusing on the explicit change of communication behavior, such as the use of interactive features and the compliance of treatment. By showing how platforms affordances changed human behavior, the study tries to underline the role of affordances in our digital lives. The overarching research question is:

RQ1: How did affordance change causally affect communication behavior, in the case of Twitter character limit increase?

\subsection{Human Agency in Technological Affordances}

It should be noted that affordance is closely related to other terms used in digital media literature such as "attribute" and "feature," but some nuances exist (Eveland, 2003; Faraj \& Azad, 2012). While objects' features are existent regardless of human presence and constant to all human actors, affordances are inherently relational, as human actors might perceive affordances and react to affordance change differently (Ellison, Gibbs, \& Weber, 2015; Fulk \& Yuan, 2013; temporary conceptualization and debates have not been settled on its ontology, such as whether or not affordances exist independently of human perceptions, most scholars agree that research should consider the role of human actors to better understand the affordance approach to the use of communication technologies (see Boyle \& Cook, 2004; Burlamaqui \& Dong, 2015; Dohn, 2009; Fayard \& Weeks, 2014; Jones, 2003; Parchoma, 2014; Sanders, 1997). Some recent theoretical developments by conceptual articles, such as "perceived affordances" and "imagined affordances" (Fox \& Holt, 2018; Nagy \& Neff, 2015; Zhao, Liu, Tang, \& Zhu, 2013), and empirical examinations of newly developed information technologies, such as blockchains and virtual reality (Shin, 2017; Shin \& Hwang, 2020), have further foregrounded the necessity to consider human agency in affordance studies.

This relational view of affordances contends that human agency, taking forms such as perceptions and interpretations, exerts influences on how affordances are eventually perceived and utilized by users for their digital behavior. It has become even more important to recognize the role of human agencies in affordances, considering the rise of "black box" technologies such 
as algorithm which does not provide an interface for users to directly engage but nonetheless manifests its action possibilities through affordances (e.g., Shin \& Park, 2019; Shin, Zhong, \& Biocca, 2020). In this sense, the call to emphasize human agency in affordance research can also be seen as a response to the sociological debate on technological determinism versus social constructivism.

In their scholarly exchange on the relationship between technological artifacts and human practices, Hutchby $(2001,2003)$ and Rappert (2003) reintroduced the technology-as-text metaphor in earlier writing (Grint \& Woolgar, 1997), which argued that the meaning of technology (text) emerges from the dynamic interaction between the developer's intentions (the writer's composition) and the user's interpretation (the reader's understanding). Overemphasis on the developer's intentions falls into the camp of technological determinism, while overemphasis on the user's interpretation falls into the camp of social constructivism, neither of which accurately represents the social reality of technology. This predicament, therefore, calls for a "third way" to understand technology in society that can reconcile these two sides, and Hutchby (2001) suggested the affordance approach as a possible answer. The definition he provides - affordances constrain the ways that technological artifacts could possibly be interpreted - incorporates both schools' theoretical arguments and gives scholars a way out from the "unpalatable choice between undersocialized and oversocialized conceptions of technology" (Bloomfield, Latham, \& Vurdubakis, 2010, p. 416). The concept of affordances has thus taken a transdisciplinary journey, transforming from a term in ecological psychology to a new yet ambivalent way to understand technology by sociologists.

In the era of mediated communication, scholars such as Neff, Jordan, McVeigh-Schultz, and Gillespie (2012) have argued that it is still relevant and important to recognize the tension between technological determinism and social constructivism as the backdrop for the increasing use of "affordances" in empirical research on digital media. In contrast to broad claims such as “technological determinism is dead" (Wyatt, 2008), Neff et al. (2012) cautioned against scholars' overcorrection in the direction of human power and advocated for the affordance approach which gives credit to both developers' and users' agencies. Applying this thinking to the case analyzed here, we would hypothesize that Twitter's character limit change might have affected its users in a nuanced way, rather than what would be simply suggested by either technological determinism or social constructivism. In other words, instead of the user population making uniform behavioral changes as intended by developers (a result expected by technological determinists) or the user population exerting agencies to resist exogenous changes (a result expected by social constructivists), we should see a mix of the two (a result suggested by the affordance approach to digital media). That is, we hypothesize that Twitter users have generally complied with the affordance change and exhibit some significant behavioral changes at the population level, but at the same time, there also exist some enormous between-subject variances driven by individual agencies.

What bears theoretical interests here is the question of why users might have changed their communication patterns to different degrees and what factors can explain those variances. Since the direct causal relationship between affordances and communication behavior is underexamined, there is limited empirical evidence to consult here, but we can make some informed speculations by extrapolating relevant research. For example, studies on community feedback and social influence have suggested that engagement indicators, such as retweets and likes, can serve as a positive or negative cue to alter users' psychological well-being and future behavior on social networking sites (e.g., Burrow \& Rainone, 2017; Cheng, 2014; Kross et al., 2013; Muchnik, 
Aral, \& Taylor, 2013). Frequent interactions with followers could thus contribute to a positive feedback loop and motivate them to use social media more (Bell, Cassarly, \& Dunbar, 2018; Utz, Tanis, \& Vermeulen, 2012; Walther et al., 2011). Therefore, it is reasonable to suspect that the degree of behavioral change might be associated with users' prior experiences on the studied social media platform. Another factor that might come into play concerns the presence and absence of communication constraint discussed in some literature on censorship and repression (e.g., Hobbs \& Roberts, 2018; Pan \& Siegel, 2020; Roberts, 2020), since Twitter extending the character limit can be understood as the platform lifting a restriction imposed by its developers earlier. The prior experiences users had with the communication constraint might consequently influence how they adapted to the new affordance when it was implemented (Boudreau \& Robey, 2005; Leonardi, 2011).

These two speculations both highlight the role of user agencies in affordances, in that Twitter users' various experiences prior to November 7, 2017 might have given them various incentives to comply with the affordance change. More details on these hypotheses will be articulated in the next section, but our second research question is clear:

RQ2: What factors, if any, can explain the various degrees to which affordance change affects communication behavior?

\section{Case, Context, and Hypotheses}

In light of the lack of empirical evidence on the causal relationship between affordances and communication behavior, the current study seeks to fill the gap in scholarly knowledge by analyzing a major event of affordance change in recent years with publicly available data sets.

The case analyzed here is Twitter increasing its character limit from 140 to 280 on November 7, 2017. According to corporate press releases, Twitter started beta-testing the extended type box in September the same year, giving some eligible users early access to the new feature, and then publicly rolled out the feature to all Twitter users two months later (Rosen \& Ihara, 2017). Twitter's initial intention is to provide users with different language preferences the same potential to express themselves on the platform, and in the meantime improve user experiences by reducing the time spent editing tweets in the composer (Rosen, 2017; Rosen \& Ihara, 2017).

This sudden intervention created a great quasi-natural experiment setting that makes the identification of causal effects possible, the intuition being that Twitter users might exhibit different communication patterns after the affordance change. However, the "experiment" did not come with random assignment and did not create a clear control group, since all Twitter users entered the new 280-character era at the same time. Time-series analysis is reasonable but might still suffer spuriousness due to history threats. Therefore, in this paper, we opted to use instrumental variable analyses - widely used in econometrics (e.g., Angrist \& Pischke, 2009) and recently gaining steam in management literature (e.g., Chintrakarn, Treepongkaruna, Jiraporn, \& Lee, 2020; Shoham, Almor, Lee, \& Ahammad, 2017) - by analyzing tweets published by temporally stable users suggested by previous literature.

More specifically, we analyzed the intervention with a randomized encouragement design, by treating tweets published by Twitter users as randomly assigned to being drafted either before or after November 7, 2017. That is, tweets that were drafted after the switch date were encouraged to use the newly expanded bandwidth, despite not all of them complying with the treatment by tweeting more than 140 characters in the end. In fact, this encouragement design 
well corresponds to the contemporary understanding of the affordance theory, as it "refutes the dichotomy between agency and determinism" (Fayard \& Weeks, 2014, p. 239). In our case, Twitter developers do not and cannot determine the behavior of their users by simply setting a new character limit, but in the meantime, it is difficult for users to exert their absolute agency to resist the technological change because their online environment has indeed changed. In other words, the relational view of technological affordances promotes the idea that technological changes encourage or nudge certain online behavior (Lee, Lee, \& Hwang, 2014; Shin et al., 2020), which the current design captures through an instrumental variable approach using a two-stage least square regression model.

However, research employing instrumental variables requires several identification assumptions, the critical one being the ignorability assumption (see Angrist, Imbens, \& Rubin, 1996; Sovey \& Green, 2011), which states that the instrument ( $Z$, in our case, a dummy indicating on the outcome ( $Y$, in our case, indicators on communication behavior), other than through its effect on the treatment assignment variable ( $T$, in our case, a dummy indicating whether a tweet used more than 140 characters). In other words, if the treatment did not happen, after the switch date, digital media users should have been tweeting in the same fashion as what they had been media use as the research context.

Organizational social media use has long been criticized by business and public relations scholars for being organization-centric and irresponsive to exogenous factors. Except few notable corporate accounts with distinct personalities such as Wendy's Twitter presence, most organizational accounts do not fully utilize social media's potentials as an interactive and two-way channel to communicate with key stakeholders. Instead, they merely broadcast corporate press releases, share news and blog links, and advertise products and promotions on social media, as evidenced by numerous studies (e.g., Ao \& Huang, 2020; Kim et al., 2014; Lovejoy \& Saxton, 2012; Qu, 2020; Waters \& Williams, 2011; Wirtz \& Zimbres, 2018; Yue, Thelen, Robinson, \& Men, 2019). Apart from the lack of human resources for organizational social media management and the persistence of information control in corporate culture, it could also be argued that, to a certain degree, affordances of Twitter as a text-based social media platform are not encouraging organizations' personnel to create relevant content for their followers or to initiate meaningful interactions with external stakeholders (Lovejoy \& Saxton, 2012; Zhou \& Xu, 2020). The insensitivity of organizational social media use to exogenous changes helped the current study fulfill the ignorability assumption. Moreover, major organizations happen to tweet a lot, which provides us a sufficient sample size for a reasonable estimation of the treatment effect.

To answer the second research question and explore why examined accounts might change their communication behavior to different degrees, two variables - user engagement level and of hypotheses, in correspondence to the two speculations articulated in the literature review section.

Social media users enjoy vastly different levels of content engagement, even when they have similar numbers of followers on the platform. Some accounts, maintained by a team of social media professionals, are much better received by Twitter users than others. By engaging stakeholders and followers with genuine conversations and generating relatable content that oftentimes goes viral, some Twitter accounts in our sample will garner higher numbers of retweets 
and likes compared to others. These high-frequency interactions with followers might give organizations and the leadership more incentive to take advantage of the increased character limit and continue improving their social media content creation to build relationships with their audiences. Therefore, it is hypothesized that active and well managed accounts with high engagement outcomes before the affordance change would use the newly extended type box more (H1.1) and increase their multimedia creation (H1.2) after the treatment. The user engagement level was numerically proxied as the median of the number of retweets and likes received by the account's pre-treatment tweets, divided by its number of followers. Medians are used to estimate average user engagement levels since the distribution of engagement indicators (i.e., retweets and likes) is highly skewed. The hypothesis is:

H1: Accounts with higher pre-treatment user engagement levels will use the newly afforded type box more often in their post-treatment tweets (H1.1) with more multimedia features (H1.2).

On the other hand, in line with Twitter's initial rationale (Rosen, 2017), it is also reasonable to expect that accounts who experienced more communication constraint pre-treatment would utilize the newly extended type box more often (H2.1) and increase their multimedia creation (H2.2). In other words, those who regularly posted tweets close to 140 characters before the affordance change might have had a hard time revising tweets over and over again to make sure their tweets did not exceed the 140 character limit. Consequently, when the constraint was released, they might take the lead to use the newly afforded feature. Perceptions of communication constraint were thus numerically proxied as the median number of characters used by the account's pre-treatment tweets. The closer the variable is to 140 , the higher communication constraint is thought to be perceived by the account. The hypothesis is:

H2: Accounts that perceived higher pre-treatment communication constraint will use the newly afforded type box more often in their post-treatment tweets (H2.1) with more multimedia features (H2.2).

\section{Method}

We selected 100 major corporations and non-profit organizations and 84 leadership accounts for the current study. Four lists were consulted and combined, including the top 50 Fortune 500 companies and the top 50 largest U.S. charities, compiled by Fortune and Forbes in 2018, 12 and leadership accounts compiled by Yue et al. (2019) and Afshar (2013). Table 1 shows the Twitter handles of those examined accounts. Aligning ourselves with principles of open science Framework (OSF) for replication purposes. We recognize the fact that the literature on digital media effects has been mostly focusing on its influence on communication behavior and user experiences on the personal level (e.g., Shin, 2017; Sun et al., 2020), despite the advantage of using organizational social media accounts for causal identification. Therefore, to provide additional evidence, we also combined these leadership accounts, representing Fortune 500 companies, startups, and political organizations, into our data collection process.

[Insert Table 1 Here]

\footnotetext{
${ }^{1}$ https://fortune.com/fortune500/2018/

${ }^{2}$ https://www.forbes.com/top-charities/list/
} 
Table 1: Examined Organizational and Leadership Twitter Handles

\begin{tabular}{|c|c|c|c|c|}
\hline \multicolumn{5}{|c|}{ Corporations } \\
\hline walmart & exxonmobil & UnitedHealthGrp & McKesson & CVSHealth \\
\hline amazon & ATT & GM & Ford & Healthcare_ABC \\
\hline Chevron & cardinalhealth & verizon & kroger & generalelectric \\
\hline Walgreens & Chase & FannieMae & Google & HomeDepot \\
\hline BankofAmerica & ExpressScripts & WellsFargo & Boeing & Phillips66Co \\
\hline AnthemInc & Microsoft & ValeroEnergy & Citi & comcast \\
\hline IBM & Dell & StateFarm & JNJCares & FreddieMac \\
\hline Target & Lowes & MarathonPetroCo & ProcterGamble & MetLife \\
\hline UPS & pepsi & intel & DowDuPontCo & ADMupdates \\
\hline Aetna & FedEx & UTC & Prudential & Albertsons \\
\hline \multicolumn{5}{|c|}{ Non-Profit Organizations } \\
\hline UnitedWay & FeedingAmerica & Americares & TFGH & SalvationArmyUS \\
\hline StJude & DirectRelief & Habitat_org & BGCA_Clubs & ymca \\
\hline FoodForThePoor & compassion & CCharitiesUSA & GoodwillIntl & SamaritansPurse \\
\hline LutheranSvcs & AmericanCancer & WorldVision & StepUp4Students & nature_org \\
\hline RedCross & American_Heart & mapintl & CMMBTweets & operationbless \\
\hline crutweets & PPFA & PAN_Foundation & UNICEFUSA & MountSinaiNYC \\
\hline SavetheChildren & CatholicRelief & MayoClinic & feedthechildren & CARE \\
\hline MSF_USA & DanaFarber & CarterCenter & Good360 & nyphospital \\
\hline HealthWellOrg & MakeAWish & shrinershosp & sloan_kettering & EIFoundation \\
\hline Rotary & TheJDC & PSIimpact & KidneyFund & ACLU \\
\hline \multicolumn{5}{|c|}{ Leadership } \\
\hline bkrunner & BruceDBroussard & ChuckRobbins & IndraNooyi & JeffBezos \\
\hline JonasPrising & KentThiry & SYFMKeane & MarkVHurd & mtbert \\
\hline mtbarra & CEOMikeJackson & RobertIger & satyanadella & SteveCollis_ABC \\
\hline SteveEasterbrk & tim_cook & LadyAshBorg & SchambachSays & ramiessaid \\
\hline valgui1 & ytechdata & ashoddd & merongribetz & JoSchneier \\
\hline AmirRubin & bjurgs & etaibeck & cjpedregal & Louel \\
\hline bgrey & jasonaramburu & DanReich & seanduffy & SameerPatel \\
\hline Benioff & richardbranson & Bill_Gross & chrisbrogan & briansolis \\
\hline Jon_Ferrara & mcuban & garyvee & jack & levie \\
\hline SteveCase & rwang0 & RomanStanek & petecashmore & SteveForbesCEO \\
\hline timoreilly & elonmusk & bhalligan & charleneli & realDonaldTrump \\
\hline MichaelDell & PeterAceto & AndrewGrill & WendySLea & BillGates \\
\hline shervin & MickyArison & markfidelman & marissamayer & rupertmurdoch \\
\hline aneelb & kevinrose & bryankramer & dens & dickc \\
\hline davemorin & ManpowerGroupJJ & MichelleRhee & invoker & davidkarp \\
\hline drewhouston & jeffweiner & jeremys & eldsjal & NPRGaryKnell \\
\hline AmFamJack & peretti & andrewmason & WesternUnionCEO & \\
\hline
\end{tabular}

\subsection{Data Collection and Variables}

We collected one year of Twitter data from the 184 accounts identified above. The tweets' publishing times range from six months before to six months after November 7, 2017 when the new character limit took effect. A web crawler in Python was used to scrape tweet IDs from 
the advanced Twitter search page, which eliminated the sampling issues caused by Twitter API's data mining rate limit and returned a complete collection of tweets published by these examined accounts. Tweets were then rehydrated to retrieve metadata for further analyses. We only used tweets with original content creation, with retweets and reply tweets - starting with “@” and were published by these 184 accounts between May 7, 2017 and May 7, 2018. Upon further examination detailed in Appendix S1, several accounts were removed due to small numbers of published tweets and being beta testers with early access. The final data set thus contains 143,771 tweets from 135 accounts.

Variables analyzed in this study include a tweet's number of characters, text characters, media, URLs, hashtags, and mentions and its publication time, all provided by the Twitter API metadata. We also constructed the number of features as the sum of numbers of media, URLs, hashtags, and mentions, to proxy the level of interactive multimedia use of a single tweet. At the account level, the number of followers was extracted from the metadata, along with two variables reated to proxy the account's engagement level with Twitter users and the account's perception of communication constraint. These two variables were created to explore why these examined accounts exhibited different communication behaviors after the affordance change, the rationale of which has been detailed in the previous section.

\subsection{Empirical Models}

As discussed earlier, it is challenging to establish the causal relationship between the treatment of whether a tweet contains more than 140 characters $(T)$ and the outcome variable of communication behavior indicators $(Y)$, because the relationship, when conventionally estimated, might suffer spuriousness and omitted variable bias due to potential confounders, such as industry types, number of followers, and corporate culture. To deal with this endogeneity issue, the two stage least squares (2SLS) regression models shown below.

$$
\begin{aligned}
& Y_{i t}=b_{2}+A_{i}+\beta_{3} \hat{T}_{i t}+\beta_{4} \hat{T}_{i t} A_{i}+\epsilon \\
& T_{i t}=b_{1}+A_{i}+\beta_{1} Z_{i t}+\beta_{2} Z_{i t} A_{i}+\epsilon
\end{aligned}
$$

[Insert Figure 1 Here]

At the first stage, $T_{i t}$ is a dummy that evaluates whether account $i$ 's tweet $t$ utilized the extended bandwidth afforded by the technological change. Tweets with more than 140 characters are labeled as 1, and those with less than 140 characters are labeled as $0 . A_{i}$ are Twitter account fixed effects, included to construct a model that accounts for all individual differences among accounts (e.g., tenure, gender, and revenues), so that we can examine within-subject behavioral changes. $Z_{i t}$ is a dummy instrument that indicates whether the publication time of account $i$ 's tweet $t$ is earlier (coded as 0 ) or later (coded as 1 ) than November 7, 2017. As we hypothesized earlier that the degrees to which examined accounts complied with the encouragement might dif$\left(A_{i}\right)$. Constant and error term are $b$ and $\epsilon$. Therefore, the first stage model can be described as: The intervention of affordance change exogenously increased the chance that a Twitter account used more than 140 characters in its tweets. This intervention might have consequently led to 
Figure 1: Research Design

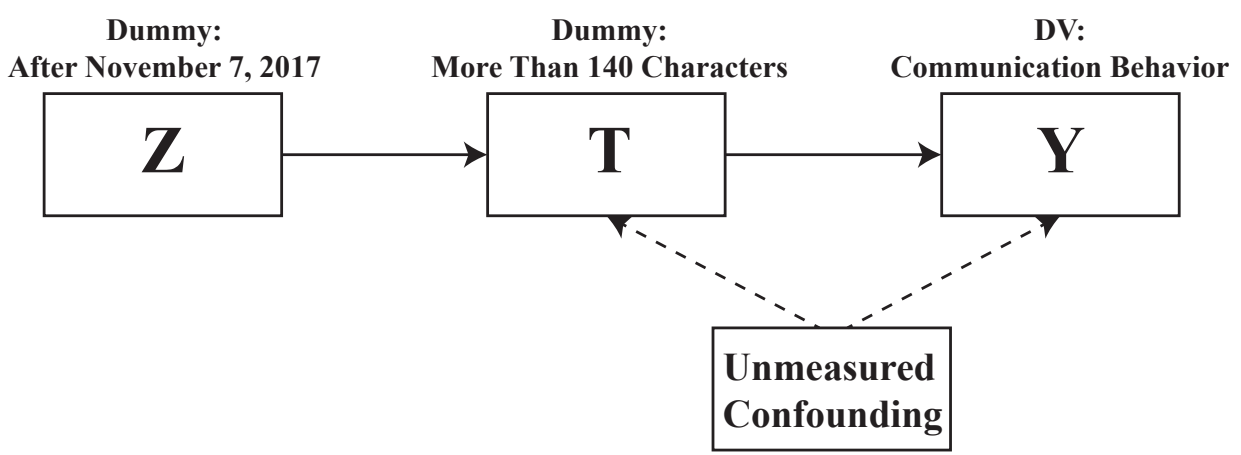

changes in communication behavior as the outcome variable $\left(Y_{i t}\right)$ modeled at the second stage.

At the second stage, we estimate how the propensity of being treated $\left(\hat{T}_{i t}\right)$, instrumented and predicted at the first stage, affected the actual communication indicators in a single tweet. $A_{i}$ are still fixed effects, and the interaction of the predicted compliance $\left(\hat{T}_{i t}\right)$ and the fixed effects $\left(A_{i}\right)$ is added to allow Twitter accounts to exhibit various degrees of behavioral change. We examined multiple dependent variables $\left(Y_{i t}\right)$, with more details provided in the online Appendix.

Therefore, in the two equations, $\beta_{1}$ and $\beta_{3}$ indicate population-level changes, as to how the newly afforded bandwidth encouraged the population of examined Twitter accounts to publish tweets that comply with the developers' intent $\left(\beta_{1}\right)$ and exhibit different communication patterns $\left(\beta_{3}\right)$. The interaction terms $\beta_{2}$ and $\beta_{4}$, in the meantime, represent the individual agency of each Twitter account. That is to say, despite the same encouragement and the universal populationways: First, the degree to which these accounts started to use more than 140 characters might vary, indicated by the coefficient $\beta_{2}$; Then, controlling the tendency to use more than 140 characters $\left(\hat{T}_{i t}\right)$, the degree of behavioral change might still vary, indicated by the coefficient $\beta_{4}$.

Before presenting the results, it should be noted that the instrumental variable design makes two other assumptions, both of which were fulfilled by the current study. First, the instrument $(Z)$ should have a strong causal effect on the treatment assignment variable $(T)$ with a rule of thumb of $F>10$. In the current data set, $F=46,185$ which indicates that $Z$ is a very strong instrument. Second, there should be no unmeasured confounders for the assignment of treatment. In our study, the treatment is assigned to the whole population, and every account November 7, 2017 has the ability to publish tweets with more than 140 characters. Similar to previous studies, the threshold determining whether or not a tweet utilized the newly afforded feature was set to 145 characters due to HTML encoding issues (Jaidka et al., 2019).

\section{Findings}

Table 2 shows the 2SLS regression result on how the affordance change affected communication behavior of the examined population of Twitter accounts. On average, the treatment of extending the character limit from 140 to 280 significantly increased the length of published tweets by 47.558 characters $(p<.001)$. In other words, controlling the degree to which these 
Table 2: 2SLS Regression Results

\begin{tabular}{|c|c|c|c|c|c|c|c|c|}
\hline & \multirow{2}{*}{$\begin{array}{c}\text { First Stage } \\
\text { Treatment } T\end{array}$} & \multicolumn{7}{|c|}{ Second Stage } \\
\hline & & Characters & Text & Mentions & Hashtags & URLs & Media & Features \\
\hline Publication Time $Z$ & $\begin{array}{l}0.700^{+* * *} \\
(0.092)\end{array}$ & & & & & & & \\
\hline Instrumented Treatment $\hat{T}$ & & $\begin{array}{l}47.558^{*+1 *} \\
(18.194)\end{array}$ & $\begin{array}{c}29.338 \\
(17.961)\end{array}$ & $\begin{array}{l}-0.039 \\
(0.355)\end{array}$ & $\begin{array}{l}-0.260 \\
(0.447)\end{array}$ & $\begin{array}{l}0.351^{\star} \\
(0.196)\end{array}$ & $\begin{array}{l}0.442^{* *} \\
(0.185)\end{array}$ & $\begin{array}{c}0.494 \\
(0.635)\end{array}$ \\
\hline Observations & 143,771 & 143,771 & 143,771 & 143,771 & 143,771 & 143,771 & 143,771 & 143,771 \\
\hline $\mathrm{R}^{2}$ & 0.426 & 0.373 & 0.377 & 0.263 & 0.362 & 0.206 & 0.319 & 0.413 \\
\hline Adjusted $\mathrm{R}^{2}$ & 0.425 & 0.371 & 0.376 & 0.261 & 0.361 & 0.204 & 0.318 & 0.412 \\
\hline Residual Std. Error $(\mathrm{df}=143501)$ & 0.291 & 40.274 & 39.758 & 0.786 & 0.990 & 0.434 & 0.411 & 1.406 \\
\hline F Statistic $(\mathrm{df}=269 ; 143501)$ & $396.604^{\star \star \star}$ & $316.748^{\star \star \star *}$ & $323.203^{\star \star \star}$ & $190.240^{\star \star \star}$ & $303.192^{\star \star \star *}$ & $138.197^{\star \star \star}$ & $249.797^{\star \star \star}$ & $374.840^{\star \star * *}$ \\
\hline
\end{tabular}

examined accounts adopted the new type box, tweets published after November 7, 2017 were significantly longer than those published before November 7, 2017.

[Insert Table 2 Here]

Those extra characters were used mainly for three purposes. First, the treatment increased the length of textual information by 29.338 characters $(p=.102)$, defined as the number of characters used by plain text, hashtags, and mentions that bear linguistic meanings. The direction of change is in line with hypothesized expectations but not statistically significant according to conventions. Second, the treatment increased the use of external links, such as corporate websites and news articles, by 0.351 more URLs per tweet $(p=.074)$. This effect is marginally significant. Third, the treatment increased the use of media, such as images and videos, by 0.442 extra unit per tweet $(p=.017)$. In summary, around two thirds of the extra 48 characters induced by affordance change were devoted to textual information, providing more linguistic clarity, while around one third of the upward change occurred because examined accounts infused their tweets with more information-rich multimedia content. The intervention brought no significant change to the population's use of mentions, hashtags, and interactive features overall.

It should be pointed out that the treatment effects on the use of characters and media reflect communication behavioral changes at different levels. While the increased number of characters might be a direct effect, as these examined accounts tried to fill the extended type box with more textual content, which was not possible before, the increased number of media cannot be explained by the same argument. As detailed in the online Appendix, characters needed to hyperlink media content did not and still do not count toward a tweet's character allowance. In other words, the ability to add media content to tweets has never been restricted, and the feature of adding images and videos to tweets received no change whatsoever on November 7, 2017. Twitter accounts were able to hyperlink media content on top of a maxed-out tweet throughout the studied period. The significant increase of media content suggests that the examined population of Twitter accounts have altered their online communication protocols after the affordance change, and started to avoid publishing plain-text tweets without multimedia content.

Therefore, the examined case of affordance change did alter communication patterns at the population level. This uniform upward shift suggests that a well-implemented technological change can induce behavioral change as originally intended. However, as detailed below, human agencies still played an important role in how these external forces were interpreted and 
Table 3: Regressions on How User Engagement Level and Communication Constraint Pre Treatment Predict Between-Subject Variances of Using More Than 140 Characters Post Treatment

\begin{tabular}{lccc}
\hline \hline & \multicolumn{3}{c}{ Interaction Coefficient $\beta_{2}$} \\
\cline { 2 - 4 } & Model 1 & Model 2 & Model 3 \\
\hline User Engagement Level & -16.224 & & 9.032 \\
& $(22.350)$ & & $(15.583)$ \\
Communication Constraint & & $0.008^{* * *}$ & $0.008^{* * *}$ \\
& & $(0.001)$ & $(0.001)$ \\
\hline Observations & 134 & 134 & 134 \\
$\mathrm{R}^{2}$ & 0.004 & 0.527 & 0.528 \\
Adjusted $\mathrm{R}^{2}$ & -0.004 & 0.523 & 0.521 \\
Residual Std. Error & $0.208(\mathrm{df}=132)$ & $0.143(\mathrm{df}=132)$ & $0.143(\mathrm{df}=131)$ \\
F Statistic & $0.527(\mathrm{df}=1 ; 132)$ & $147.029^{* * *}(\mathrm{df}=1 ; 132)$ & $73.312^{* * *}(\mathrm{df}=2 ; 131)$ \\
\hline \hline Note: & & & ${ }^{*} \mathrm{p}<0.1 ;{ }^{* *} \mathrm{p}<0.05 ;{ }^{* * *} \mathrm{p}<0.01$
\end{tabular}

incorporated.

A closer look at between-subject differences shows that the effect of affordance change on communication behavior vastly varies across examined accounts. For instance, indicated by the interaction coefficient $\beta_{4}$ with more details shown in Appendix Figure 2, the effect of affordance change on the number of characters used by organizational and leadership tweets showed huge variances. Pepsi, after the character limit change, posted more concise tweets instead $\left(\beta_{4}=-338.831, p<.001\right)$, while the positive effect of affordance change on the number of characters was more prominent for Target $\left(\beta_{4}=176.788, p<.01\right)$. The finding stays true for other kinds of feature use, for example the use of media shown in Appendix Figure 3.

To answer the second research question, the study continued to explore what factors mainly contributed to the various effect sizes of affordance change on social media use. Regressing interaction coefficients $\beta_{2}$ on the two hypothesized contributing factors, Table 3 shows of communication constraint $(\beta=.008, p<.001)$. The effect of social expectation, proxied as the user engagement level before the treatment, is not statistically significant. Hypotheses H1.1 is thus not supported, while H2.1 is supported. Noticeable is the fact that the previous perception of communication constraint has a huge explanation power $\left(R^{2}=0.527\right)$, indicating that the between-subject variances among examined Twitter accounts can be well explained by their previous perceptions. In other words, accounts that perceived more communication constraint those whose pre-treatment tweets constantly hit close to the 140 character threshold - were more affected by the affordance change and more likely to use the extended type box post-treatment. This finding is also illustrated in Figure 2, which plots the instrumented treatment compliance variable $\hat{T}_{i}$ against the communication constraint proxy variable.

[Insert Table 3 Here]

[Insert Figure 2 Here]

Regressing interaction coefficients $\beta_{4}$ on the two hypothesized contributing factors, the 
Figure 2: Effects of Communication Constraint Perceptions on Later Behavioral Change

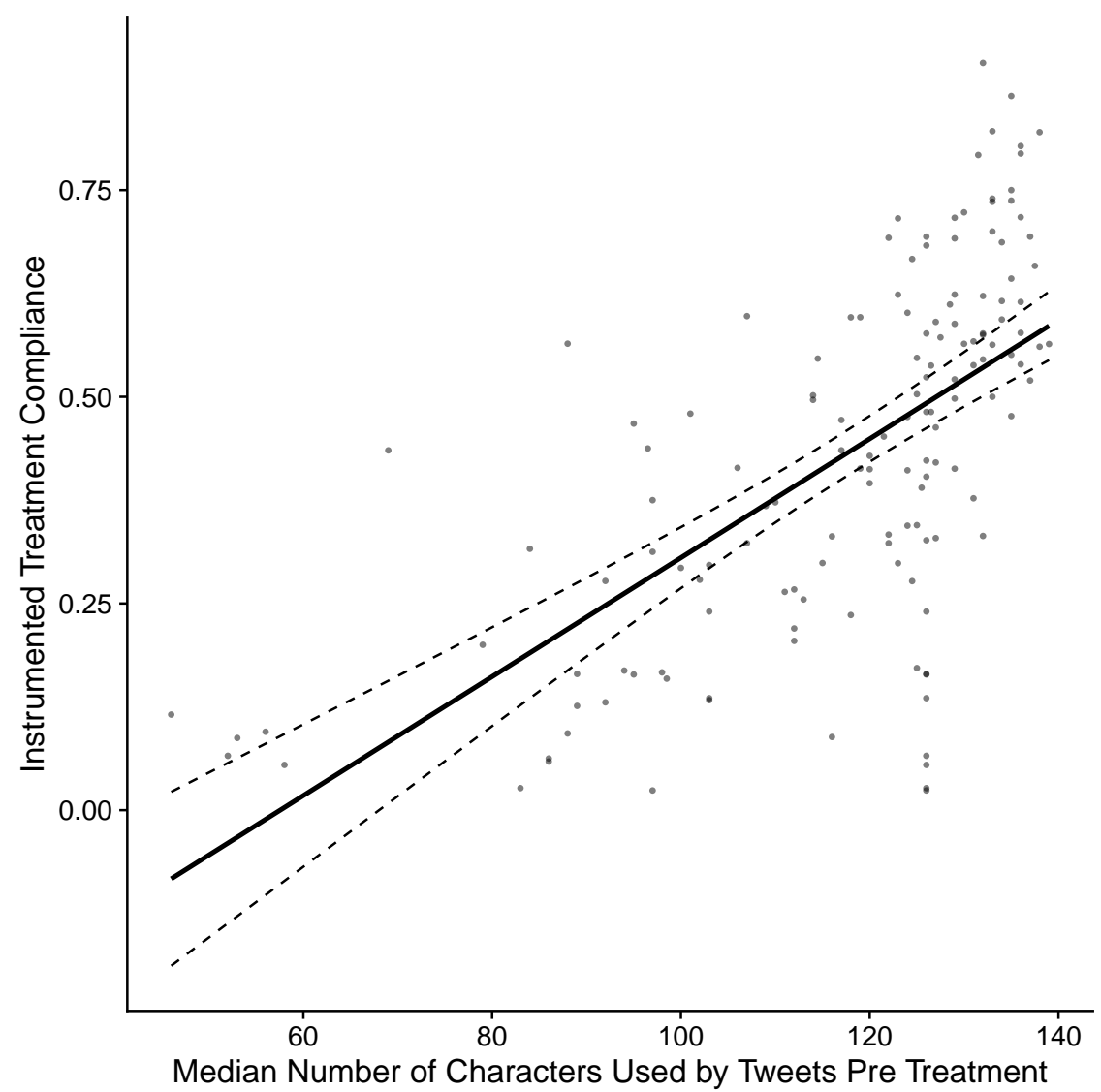

Note: The figure, corresponding to the first stage regression model (OLS) in Table 2, plots the predicted and instrumented treatment compliance rate $\hat{T}_{i}$ after November 7, 2017 against the median number of characters used by examined Twitter accounts prior to November 7, 2017. Dots represent observations of social media use, and dotted lines represent $95 \%$ confidence intervals of the solid linear regression line. The figure shows that perceptions of higher communication constraints prior to the intervention are associated with greater communication behavioral change after the intervention.

study finds that the degree to which affordance change affects Twitter feature use was generally not associated with either user engagement level or perceived communication constraint. More details can be found in Appendix Table 2. Hypotheses H1.2 and H2.2 were thus rejected.

In summary, the investigation shows that although the affordance change resulted in some population-level behavioral changes in major organizations and leadership's online communication, the effect hugely varied across Twitter accounts. Affordance change did not affect communicative agents uniformly, instead, previous endogenous factors moderate the degree to which communication behavior adapted to the exogenous change. The result highlights the role of human agencies in the face of technological changes, and provides empirical support for the affordances approach as a reconciliation between technological determinism and social construc- 
tivism.

\section{Discussion}

By analyzing a major event of affordance change, the study documents evidence on the

440

causal link between affordances and mediated communication patterns, and explicates how social media users adjusted their digital behavior in response to a technological change. Complementing works that examined social networking sites with an affordance approach (e.g., Fox \& Holt, 2018; Nagy \& Neff, 2015) and theorized the role of user perceptions and experiences in media affordances (e.g., Shin, 2019; Zhao et al., 2013), the results highlight the necessity of considering human agencies when studying communication behavior on digital channels. By showing that users' future behavior generally complies with developers' original intent but heavily deviates from each other due to previous perceptions and experiences, the findings demonstrate the value of using affordances as a third way to understand information communication technologies in society, which recognizes the relational dynamics between human behavior and technological artifacts and does not fall into the traps of technological determinism and social constructivism.

One contribution of this study is the direct assessment of the causal effect of affordance change on communication behavior. Despite the prevalence of the term "affordances" in digital media research, little attention has been paid to evaluate its direct connection with how users actually communicate on digital media platforms. Comparative, critical, and theoretical pieces (e.g., Oz et al., 2018; Schrock, 2015) have long been contextualizing their empirical findings within the framework of affordances and claiming that social media affordances are the contributing factor that drives various communication behavior across popular networking sites. The hypothesis is intuitive, but as reviewed in earlier sections, empirical evidence on the connection remains elusive. The heavily publicized instance of affordance change, analyzed in the current study with 2SLS, was a rare case where the causal effect of affordance change on communication behavior can be precisely captured, examined, and quantified. By showing how a group of representative tweeters adjusted their communication patterns post-treatment, the paper serves as an important footnote on how affordance, as a central concept in the literature that theorizes the impact of digital technology, drives our digital behavior and influences our digital world, and how social media platforms have been designed and can be designed to invoke desired prosocial behavior (Aakhus, 2007; Gillespie, 2010).

The second contribution of this study is the provision of robust evidence on the role of human agencies in the face of technological affordance changes. As demonstrated in the study, the affordance change does not affect users in a uniform way, instead, the effect varies across accounts and conditions upon their previous experiences on the social media platform. Their levels of perceived communication constraint influence their degrees of reaction, especially on the use of the extended type box. The finding on communication constraint highlights the importance of conceptualizing affordance as a product that is constantly influenced by human perceptions, in that users can perceive the same communication channel differently and can consequently have various experiences of the affordance change (Fox \& McEwan, 2017; Graves, 2007). This finding also connects with the emergent human-computer interaction literature that explored affordances of recent information communication technologies that cannot be investigated in conventional ways, one example being algorithm's affordances (e.g., Shin \& Park, 2019). Uncertainties brought by this intangible technology further underline the fact that technology is more than mechanical 
artifacts and "technical qualities such as prediction and accuracy" (Shin et al., 2020, p. 8), and that it is more critical than ever to advance a user-centric view of how humans interpret and process technological changes.

The third contribution of this study is its theoretical implication for the affordance approach to understanding technology (especially digital media platforms) in society. Evidence presented in the manuscript contributes to previous arguments on how researchers should understand affordances in digital media research, considering the long history of theoretical tension between technological determinism and social constructivism. For example, Nagy and Neff (2015) presented affordances as "a kind of middle ground between technological determinism and social construction" (p. 2), where the materiality of technology designed by developers and the interpretation of technology initiated by users interact and contest. Similarly, Hogan (2009) found both technological determinism and social constructivism to be polar understandings of technology use, and as shown by the current study, the affordance approach - taking a more neutral stand on the issue, giving both schools their deserved credit, and acknowledging both entities' (i.e., developers' and users') agencies during the process - can better explain communication behavior on digital media platforms. Therefore, despite establishing the causal link between affordance change and communication behavioral change, this case study does not assert a deterministic view on the role of affordances in human communication. Instead, the clear evidence of causality only exists at the first stage of the 2SLS model, and it is indeed users' various interpretations of how the technological change can be utilized for communicative purposes that are driving the behavioral indicators captured by our statistical models. For example, examined users did not consequently mention more people, use more hashtags, or even put in more textual information (see Table 2). The encouragement (nudge) administered by developers remains merely an encouragement (nudge) for users. In this sense, the analysis reported in this paper provides theoretical interesting and empirically sound evidence for the affordance approach to digital media, in that developers' designs do not determine communication behavior and user agencies do not determine communication behavior either. It is the interaction between developer intent and user experiences that is shaping how digital communication takes shape on Twitter.

The fourth contribution of the study relates to the research context of organizational social media use. Existing literature has long been fixating on why organizations only use social media for one-way communication to serve their business purposes (e.g., Lovejoy \& Saxton, 2012), despite the clear evidence of how interactive engagement can benefit them in situations such as corporate crises (e.g., Xu \& Xiong, 2020; Xu \& Zhou, 2020) and intercultural communication (e.g., Al-Kandari, Gaither, Alfahad, Dashti, \& Alsaber, 2019). In other words, these previous studies attribute the blame to communicative agents in the process. But as the current study evinced, social media's technological affordances could also play a huge role in determining what kinds of public communication emerges on these platforms. The different ways users - including organizations' management teams and ordinary stakeholders - perceive affordances can thus affect the communication process that bears critical consequences for business success. In this sense, the current paper also echoes with some new management literature that examined external and internal communication challenges from the affordances perspective (e.g., Argyris \& Monu, 2015; Ellmer \& Reichel, 2020), and argues that scholars should consider incorporating affordance theory into their empirical inquiries to better understand why organizations behave in a certain way on social media. In fact, recent insights from Davies and Hobbs (2020) have found that digital media's affordances can sometimes encourage or nudge social media influencers to engage 
in propagandistic communication practice and violate the normative guidelines of ethical public relations (Kent \& Li, 2020), without serious ramifications from regulatory entities. Though a discussion on how communication patterns invoked by digital media affordances could create negative consequences for the general society is far beyond the scope of our study, the current paper does highlight the fact that technological changes implemented by information technology companies can exert profound effects on organizations' and organizational personnel's communication behavior, and that affordance theory can be employed to produce new scholarly insights on this important topic.

\section{Limitations and Future Directions}

The identification of causal effects requires researchers to analyze a precise but small intervention. Therefore, the current study naturally lacks the external validity to illustrate how another kind of affordance change might affect communication behavior in the same causal manner. This limitation is baked into the study design, but it also creates new venues for future qualitative and mixed-method research to contextualize our results and provide more granular analyses on how affordance changes could induce communication behavioral changes. For example, our findings showed that, although the ability to add media content did not receive any immediate change due to the character expansion, examined accounts started posting more images and videos in response. It is likely that some organizations restructured their social media guidelines because of the affordance change, and there might be other mechanisms that are unknown to authors that produced the results uncovered by our computational analysis. Without interviewing these teams and personnels or conducting a content analysis of collected tweets, it is difficult to specify these mechanisms and substantiate these claims.

Another limitation of the current study is the lack of a sociological inquiry into our second research question. Social media users behave in an ecosystem where they constantly interact with each other, and their behavior is not completely bounded by their psychological perceptions of previous experiences or expectations as we hypothesized. Digital media creates digital organization-public relationships (Lock, 2019) that promote behavioral contagion that is not captured by the current study. In other words, the reason why these examined social media accounts exhibited behavioral changes might be that they were following suit and imitating other users, and the two proposed hypotheses - focusing on user engagement and constraint perceptions failed to test this possibility. Future research can construct these accounts' ego networks (e.g., the concerned account's followings and followers), collect data on these accounts' posting histories, and examine whether intercorrelations exist among those connected users. Scholars can also inquire whether and how user attributes correlate with behavioral changes by labeling accounts with variables that have been found to affect organizational and leadership communication patterns, such as strategic purposes, gender, and prestige (e.g., Fu \& Zhang, 2019; Sommerfeldt, Yang, \& Taylor, 2019; Yue, Chung, Kelleher, Bradshaw, \& Ferguson, 2020).

Last but not least, the current study signals a future direction for digital media literature to examine technical interventions from an affordance perspective. Although a lot of $\mathrm{A} / \mathrm{B}$ testings executed by information technology companies either do not amount to a change of affordance (e.g., Matias, 2019) or are conducted in house without public datasets available as we previously discussed (e.g., Kramer, Guillory, \& Hancock, 2014), it remains a fact that these digital trace data are becoming readily available due to the increasing use of computational tools developed for 
social science researchers. By streaming data from platforms that provide public data access, such as Twitter and Reddit, monitoring minor technical changes implemented by the company, and 570 analyzing logged user behavioral data with an instrumental variable approach demonstrated here, scholars can accumulate more empirical evidence on how affordances change communication behavior and our digital media ecology at large. 


\section{References}

Aakhus, M. (2007). Communication as design. Communication Monographs, 74(1), 112-117. doi: $10.1080 / 03637750701196383$

Afshar, V. (2013). The top 50 social chief executive officers (CEOs) on Twitter. HuffPost. Retrieved from https : / / www. huffpost.com/entry/the-top-50-social-chief -e_b_3380055

Al-Kandari, A. A., Gaither, T. K., Alfahad, M. M., Dashti, A. A., \& Alsaber, A. R. (2019). An Arab perspective on social media: How banks in Kuwait use instagram for public relations. Public Relations Review, 45(3), 101774. doi: 10.1016/j.pubrev.2019.04.007

Angrist, J. D., Imbens, G. W., \& Rubin, D. B. (1996). Identification of causal effects using instrumental variables. Journal of the American Statistical Association, 91(434), 444-455. doi: 10.1080/01621459.1996.10476902

Angrist, J. D., \& Pischke, J.-S. (2009). Mostly harmless econometrics: An empiricist's companion. Princeton University Press.

Ao, S. H., \& Huang, Q. S. (2020). A systematic review on the application of dialogue in public relations to information communication technology-based platforms: Comparing English and Chinese contexts. Public Relations Review, 46(1), 101814. doi: 10.1016/j.pubrev.2019 .101814

Argyris, Y. A., \& Monu, K. (2015). Corporate use of social media: Technology affordance and external stakeholder relations. Fournal of Organizational Computing and Electronic Commerce, 25(2), 140-168. doi: 10.1080/10919392.2015.1033940

Bell, B. T., Cassarly, J. A., \& Dunbar, L. (2018). Self-objectification and positive feedback ("likes”) are associated with frequency of posting sexually objectifying self-images on social media. Body Image, 26, 83-89. doi: 10.1016/j.bodyim.2018.06.005

Bloomfield, B. P., Latham, Y., \& Vurdubakis, T. (2010). Bodies, technologies and action possibilities: When is an affordance? Sociology, 44(3), 415-433. doi: 10.1177/0038038510362469

Boudreau, M.-C., \& Robey, D. (2005). Enacting integrated information technology: A human agency perspective. Organization Science, 16(1), 3-18. doi: 10.1287/orsc.1040.0103

Boyle, T., \& Cook, J. (2004). Understanding and using technological affordances: A commentary on Conole and Dyke. Research in Learning Technology, 12(3), 295-299. doi: $10.1080 / 0968776042000259591$

Burlamaqui, L., \& Dong, A. (2015). The use and misuse of the concept of affordance. In J. S. Gero \& S. Hanna (Eds.), Design Computing and Cognition '14 (pp. 295-311). Springer. doi: 10.1007/ 978-3-319-14956-1_17

Burrow, A. L., \& Rainone, N. (2017). How many likes did I get?: Purpose moderates links between positive social media feedback and self-esteem. Journal of Experimental Social Psychology, 69, 232-236. doi: 10.1016/j.jesp.2016.09.005

Chan, L. S. (2018). Ambivalence in networked intimacy: Observations from gay men using mobile dating apps. New Media \& Society, 20(7), 2566-2581. doi: 10.1177/1461444817727156

Chen, G. M. (2011). Tweet this: A uses and gratifications perspective on how active Twitter use gratifies a need to connect with others. Computers in Human Behavior, 27(2), 755-762. doi: 10.1016/j.chb.2010.10.023

Cheng, J. (2014). How community feedback shapes user behavior. In Proceedings of the Eighth International AAAI Conference on Weblogs and Social Media (ICWSM 2014) (pp. 41-50). 
Chintrakarn, P., Treepongkaruna, S., Jiraporn, P., \& Lee, S. M. (2020). Do LGBT-supportive corporate policies improve credit ratings? An instrumental-variable analysis. Fournal of Business Ethics, 162(1), 31-45. doi: 10.1007/s10551-018-4009-9

Davies, C., \& Hobbs, M. (2020). Irresistible possibilities: Examining the uses and consequences of social media influencers for contemporary public relations. Public Relations Review, 46(5), 101983. doi: 10.1016/j.pubrev.2020.101983

Dohn, N. B. (2009). Affordances revisited: Articulating a Merleau-Pontian view. International fournal of Computer-Supported Collaborative Learning, 4(2), 151-170. doi: 10.1007/s11412 -009-9062-z

Ellison, N. B., Gibbs, J. L., \& Weber, M. S. (2015). The use of enterprise social network sites for knowledge sharing in distributed organizations: The role of organizational affordances. American Behavioral Scientist, 59(1), 103-123. doi: 10.1177/0002764214540510

Ellmer, M., \& Reichel, A. (2020). Mind the channel! An affordance perspective on how digital voice channels encourage or discourage employee voice. Human Resource Management Journal, 1748-8583.12297. doi: 10.1111/1748-8583.12297

Evans, S. K., Pearce, K. E., Vitak, J., \& Treem, J. W. (2017). Explicating affordances: A conceptual framework for understanding affordances in communication research. Fournal of ComputerMediated Communication, 22(1), 35-52. doi: 10.1111/jcc4.12180

Eveland, W. P. (2003). A "mix of attributes" approach to the study of media effects and new communication technologies. Journal of Communication, 53(3), 395-410. doi: 10.1111/ j.1460-2466.2003.tb02598.x

Faraj, S., \& Azad, B. (2012). The materiality of technology: An affordance perspective. In P. M. Leonardi, B. A. Nardi, \& J. Kallinikos (Eds.), Materiality and organizing: Social interaction in a technological world (pp. 237-258). Oxford University Press.

Fayard, A.-L., \& Weeks, J. (2014). Affordances for practice. Information and Organization, 24(4), 236-249. doi: 10.1016/j.infoandorg.2014.10.001

Fox, J., \& Holt, L. F. (2018). Fear of isolation and perceived affordances: The spiral of silence on social networking sites regarding police discrimination. Mass Communication and Society, 21(5), 533-554. doi: 10.1080/15205436.2018.1442480

Fox, J., \& McEwan, B. (2017). Distinguishing technologies for social interaction: The perceived social affordances of communication channels scale. Communication Monographs, 84(3), 298-318. doi: 10.1080/03637751.2017.1332418

Fox, J., \& Warber, K. M. (2015). Queer identity management and political self-expression on social networking sites: A co-cultural approach to the spiral of silence. Fournal of Communication, 65(1), 79-100. doi: 10.1111/jcom.12137

Fu, J. S., \& Zhang, R. (2019). NGOs' HIV/AIDS discourse on social media and websites: Technology affordances and strategic communication across media platforms. International fournal of Communication, 13, 181-205.

Fulk, J., \& Yuan, Y. C. (2013). Location, motivation, and social capitalization via enterprise social networking. Journal of Computer-Mediated Communication, 19(1), 20-37. doi: 10.1111/ jcc4.12033

Gibbs, J. L., Rozaidi, N. A., \& Eisenberg, J. (2013). Overcoming the "ideology of openness": Probing the affordances of social media for organizational knowledge sharing. Fournal of Computer-Mediated Communication, 19(1), 102-120. doi: 10.1111/jcc4.12034

Gibson, J. J. (1979). The ecological approach to visual perception. Houghton Mifflin. 
Gillespie, T. (2010). The politics of 'platforms'. New Media \& Society, 12(3), 347-364. doi: $10.1177 / 1461444809342738$

Gligorić, K., Anderson, A., \& West, R. (2018). How constraints affect content: The case of Twitter's switch from 140 to 280 characters. In Proceedings of the Twelfth International AAAI Conference on Web and Social Media (ICWSM 2018) (pp. 596-599).

Gligorić, K., Anderson, A., \& West, R. (2019). Causal effects of brevity on style and success in social media. Proceedings of the ACM on Human-Computer Interaction, 3(CSCW), 1-23. doi: $10.1145 / 3359147$

Gligorić, K., Anderson, A., \& West, R. (2020). Adoption of Twitter's new length limit: Is 280 the new 140? arXiv:2009.07661 [cs].

Graves, L. (2007). The affordances of blogging: A case study in culture and technological effects. fournal of Communication Inquiry, 31(4), 331-346. doi: 10.1177/0196859907305446

Greeno, J. G. (1994). Gibson's affordances. Psychological Review, 101(2), 336-342. doi: 10.1037/ 0033-295X.101.2.336

Grint, K., \& Woolgar, S. (1997). The machine at work: Technology, work, and organization. Polity Press.

Halpern, D., \& Gibbs, J. (2013). Social media as a catalyst for online deliberation? Exploring the affordances of Facebook and YouTube for political expression. Computers in Human Behavior, 29(3), 1159-1168. doi: 10.1016/j.chb.2012.10.008

Hobbs, W. R., \& Roberts, M. E. (2018). How sudden censorship can increase access to information. American Political Science Review, 112(3), 621-636. doi: 10.1017/S0003055418000084

Hogan, B. J. (2009). Networking in everyday life (Doctoral Dissertation). University of Toronto, Toronto, Ontario, Canada..

Hutchby, I. (2001). Technologies, texts and affordances. Sociology, 35(2), 441-456. doi: 10.1177/ S0038038501000219

Hutchby, I. (2003). Affordances and the analysis of technologically mediated interaction: A response to Brian Rappert. Sociology, 37(3), 581-589. doi: 10.1177/00380385030373011

Jaidka, K., Guntuku, S. C., Buffone, A., Schwartz, H. A., \& Ungar, L. (2018). Facebook vs. Twitter: Differences in self-disclosure and trait prediction. In Proceedings of the International AAAI Conference on Web and Social Media.

Jaidka, K., Zhou, A., \& Lelkes, Y. (2019). Brevity is the soul of Twitter: The constraint affordance and political discussion. fournal of Communication, 69(4), 345-372. doi: 10.1093/joc/jqz023

Jones, K. S. (2003). What is an affordance? Ecological Psychology, 15(2), 107-114. doi: 10.1207/ S15326969ECO1502_1

Kaptelinin, V., \& Nardi, B. (2012). Affordances in HCI: Toward a mediated action perspective. In Proceedings of the 2012 ACM annual conference on Human Factors in Computing Systems CHI '12 (p. 967). Austin, Texas, USA: ACM Press. doi: 10.1145/2207676.2208541

Kent, M. L., \& Li, C. (2020). Toward a normative social media theory for public relations. Public Relations Review, 46(1), 101857. doi: 10.1016/j.pubrev.2019.101857

Kim, D., Chun, H., Kwak, Y., \& Nam, Y. (2014). The employment of dialogic principles in website, Facebook, and Twitter platforms of environmental nonprofit organizations. Social Science Computer Review, 32(5), 590-605. doi: 10.1177/0894439314525752

Kramer, A. D. I., Guillory, J. E., \& Hancock, J. T. (2014). Experimental evidence of massivescale emotional contagion through social networks. Proceedings of the National Academy of Sciences, 111(24), 8788-8790. doi: 10.1073/pnas.1320040111 
Kross, E., Verduyn, P., Demiralp, E., Park, J., Lee, D. S., Lin, N., ... Ybarra, O. (2013). Facebook use predicts declines in subjective well-being in young adults. PLoS ONE, 8(8), e69841. doi: 10.1371/journal.pone.0069841

Lee, K. C., Lee, S., \& Hwang, Y. (2014). The impact of hyperlink affordance, psychological reactance, and perceived business tie on trust transfer. Computers in Human Behavior, 30, 110-120. doi: 10.1016/j.chb.2013.08.003

Leonardi. (2011). When flexible routines meet flexible technologies: Affordance, constraint, and the imbrication of human and material agencies. MIS Quarterly, 35(1), 147. doi: 10.2307/ 23043493

Lintern, G. (2000). An affordance-based perspective on human-machine interface design. Ecological Psychology, 12(1), 65-69. doi: 10.1207/S15326969ECO1201_7

Lock, I. (2019). Explicating communicative organization-stakeholder relationships in the digital age: A systematic review and research agenda. Public Relations Review, 45(4), 101829. doi: 10.1016/j.pubrev.2019.101829

Lovejoy, K., \& Saxton, G. D. (2012). Information, community, and action: How nonprofit organizations use social media. fournal of Computer-Mediated Communication, 17(3), 337-353. doi: $10.1111 /$ j.1083-6101.2012.01576.x

Matias, J. N. (2019). Preventing harassment and increasing group participation through social norms in 2,190 online science discussions. Proceedings of the National Academy of Sciences, 116(20), 9785-9789. doi: 10.1073/pnas.1813486116

McGrenere, J., \& Ho, W. (2000). Affordances: Clarifying and evolving a concept. In Proceedings of Graphics Interface 2000 (pp. 179-186). Montréal, Québec, Canada. doi: 10.20380/GI2000.24

McGuigan, L. (2019). Automating the audience commodity: The unacknowledged ancestry of programmatic advertising. New Media \& Society, 21(11-12), 2366-2385. doi: 10.1177/ 1461444819846449

Muchnik, L., Aral, S., \& Taylor, S. J. (2013). Social influence bias: A randomized experiment. Science, 341(6146), 647-651. doi: 10.1126/science.1240466

Nagy, P., \& Neff, G. (2015). Imagined affordance: Reconstructing a keyword for communication theory. Social Media + Society, 1(2), 205630511560338. doi: 10.1177/2056305115603385

Neff, G., Jordan, T., McVeigh-Schultz, J., \& Gillespie, T. (2012). Affordances, technical agency, and the politics of technologies of cultural production. Fournal of Broadcasting \& Electronic Media, 56(2), 299-313. doi: 10.1080/08838151.2012.678520

Norman, D. A. (1988). The design of everyday things. Basic Books.

Oz, M., Zheng, P., \& Chen, G. M. (2018). Twitter versus Facebook: Comparing incivility, impoliteness, and deliberative attributes. New Media \& Society, 20(9), 3400-3419. doi: $10.1177 / 1461444817749516$

Pan, J., \& Siegel, A. A. (2020). How Saudi crackdowns fail to silence online dissent. American Political Science Review, 114(1), 109-125. doi: 10.1017/S0003055419000650

Parchoma, G. (2014). The contested ontology of affordances: Implications for researching technological affordances for collaborative knowledge production. Computers in Human Behavior, 37, 360-368. doi: 10.1016/j.chb.2012.05.028

Park, Y. J., \& Yang, G. S. (2017). Personal network on the Internet: How the socially marginalized stay marginalized in personal network diversity and multiplicity. Telematics and Informatics, 34(1), 1-10. doi: 10.1016/j.tele.2016.04.001

Qu, Y. (2020). Engaging publics in the mobile era: A study of Chinese charitable foundations' use 
of WeChat. Public Relations Review, 46(1), 101815. doi: 10.1016/j.pubrev.2019.101815

Rappert, B. (2003). Technologies, texts and possibilities: A reply to Hutchby. Sociology, 37(3), 565-580. doi: 10.1177/00380385030373010

Reicher, S. D., Spears, R., \& Postmes, T. (1995). A social identity model of deindividuation phenomena. European Review of Social Psychology, 6(1), 161-198. doi: 10.1080/14792779443000049

Roberts, M. E. (2020). Resilience to online censorship. Annual Review of Political Science, 23(1), 401-419. doi: 10.1146/annurev-polisci-050718-032837

Rosen, A. (2017). Tweeting made easier. Retrieved from https : //blog.twitter.com/ official/en_us/topics/product/2017/tweetingmadeeasier . html

Rosen, A., \& Ihara, I. (2017). Giving you more characters to express yourself. Retrieved from https://blog.twitter.com/official/en_us/topics/product/ 2017 /Giving-you-more-characters-to-express-yourself .html

Sanders, J. T. (1997). An ontology of affordances. Ecological Psychology, 9(1), 97-112. doi: 10.1207/s15326969eco0901_4

Schrock, A. R. (2015). Communicative affordances of mobile media: Portability, availability, locatability, and multimediality. International fournal of Communication, 9, 1229-1246.

Shin, D. (2017). The role of affordance in the experience of virtual reality learning: Technological and affective affordances in virtual reality. Telematics and Informatics, 34(8), 1826-1836. doi: $10.1016 /$ j.tele.2017.05.013

Shin, D. (2019). How do technological properties influence user affordance of wearable technologies? Interaction Studies, 20(2), 307-338. doi: 10.1075/is.16024.shi

Shin, D., \& Hwang, Y. (2020). The effects of security and traceability of blockchain on digital affordance. Online Information Review, 44(4), 913-932. doi: 10.1108/OIR-01-2019-0013

Shin, D., \& Park, Y. J. (2019). Role of fairness, accountability, and transparency in algorithmic affordance. Computers in Human Behavior, 98, 277-284. doi: 10.1016/j.chb.2019.04.019

Shin, D., Zhong, B., \& Biocca, F. A. (2020). Beyond user experience: What constitutes algorithmic experiences? International Journal of Information Management, 52, 102061. doi: 10.1016/ j.ijinfomgt.2019.102061

Shoham, A., Almor, T., Lee, S. M., \& Ahammad, M. F. (2017). Encouraging environmental sustainability through gender: A micro-foundational approach using linguistic gender marking: Environmental sustainability through gender. Fournal of Organizational Behavior, 38(9), 1356-1379. doi: 10.1002/job.2188

Sommerfeldt, E. J., Yang, A., \& Taylor, M. (2019). Public relations channel "repertoires": Exploring patterns of channel use in practice. Public Relations Review, 45(4), 101796. doi: 10.1016/ j.pubrev.2019.101796

Sovey, A. J., \& Green, D. P. (2011). Instrumental variables estimation in political science: A readers' guide. American fournal of Political Science, 55(1), 188-200. doi: 10.1111/j.1540 $-5907.2010 .00477 . \mathrm{x}$

Sun, Y., Wang, C., \& Jeyaraj, A. (2020). Enterprise social media affordances as enablers of knowledge transfer and creative performance: An empirical study. Telematics and Informatics, 51, 101402. doi: 10.1016/j.tele.2020.101402

Sundar, S. S. (2008). The MAIN model: A heuristic approach to understanding technology effects on credibility. In M. J. Metzger \& A. J. Flanagin (Eds.), Digital media, youth, and credibility (pp. 73-100). MIT Press. 
Taipale, S. (2014). The affordances of reading/writing on paper and digitally in Finland. Telematics and Informatics, 31(4), 532-542. doi: 10.1016/j.tele.2013.11.003

Treem, J. W., \& Leonardi, P. M. (2013). Social media use in organizations: Exploring the affordances of visibility, editability, persistence, and association. Annals of the International Communication Association, 36(1), 143-189. doi: 10.1080/23808985.2013.11679130

Utz, S., Tanis, M., \& Vermeulen, I. (2012). It is all about being popular: The effects of need for popularity on social network site use. Cyberpsychology, Behavior, and Social Networking, 15(1), 37-42. doi: 10.1089/cyber.2010.0651

Walther, J. B., Liang, Y. J., DeAndrea, D. C., Tong, S. T., Carr, C. T., Spottswood, E. L., \& AmichaiHamburger, Y. (2011). The effect of feedback on identity shift in computer-mediated communication. Media Psychology, 14(1), 1-26. doi: 10.1080/15213269.2010.547832

Waters, R. D., \& Williams, J. M. (2011). Squawking, tweeting, cooing, and hooting: Analyzing the communication patterns of government agencies on Twitter. Fournal of Public Affairs, 11(4), 353-363. doi: 10.1002/pa.385

Wirtz, J. G., \& Zimbres, T. M. (2018). A systematic analysis of research applying 'principles of dialogic communication' to organizational websites, blogs, and social media: Implications for theory and practice. Journal of Public Relations Research, 30(1-2), 5-34. doi: 10.1080/ 1062726X.2018.1455146

Wyatt, S. (2008). Technological determinism Is dead; Long live technological determinism. In E. J. Hackett, O. Amsterdamska, M. Lynch, \& J. Wajcman (Eds.), The handbook of science \& technology studies (3rd ed., pp. 165-181). MIT Press.

Xu, S., \& Xiong, Y. (2020). Setting socially mediated engagement parameters: A topic modeling and text analytic approach to examining polarized discourses on Gillette's campaign. Public Relations Review, 46(5), 101959. doi: 10.1016/j.pubrev.2020.101959

$\mathrm{Xu}$, S., \& Zhou, A. (2020). Hashtag homophily in twitter network: Examining a controversial cause-related marketing campaign. Computers in Human Behavior, 102, 87-96. doi: 10.1016/ j.chb.2019.08.006

Yue, C. A., Chung, Y. J., Kelleher, T., Bradshaw, A. S., \& Ferguson, M. A. (2020). How CEO social media disclosure and gender affect perceived CEO attributes, relationship investment, and engagement intention. Journalism \& Mass Communication Quarterly. doi: $10.1177 / 1077699020943521$

Yue, C. A., Thelen, P., Robinson, K., \& Men, L. R. (2019). How do CEOs communicate on Twitter? A comparative study between Fortune 200 companies and top startup companies. Corporate Communications: An International fournal, 24(3), 532-552. doi: 10.1108/CCIJ-03-2019-0031

Zhao, Y., Liu, J., Tang, J., \& Zhu, Q. (2013). Conceptualizing perceived affordances in social media interaction design. Aslib Proceedings, 65(3), 289-303. doi: 10.1108/00012531311330656

Zhou, A., \& Xu, S. (2020). Digital public relations through the lens of affordances: A conceptual update of the "ease of interface" dialogic principle. Available at SocArxiv. doi: 10.31235/ osf.io/uzhk9 


\section{Appendix}

\subsection{Data Description}

The main text reads that the original data set is a complete collection of original tweets $(N=151,780)$ that were published by the top 50 Fortune 500 companies (according to the Forbes 2018 list), the top 50 largest U.S. charities (according to the Forbes 2018 list), and 84 social leadership accounts compiled by Yue, Thelen, Robinson, and Men (2019) and Afshar (2013) between May 7, 2017 and May 7, 2018. Among examined accounts, two are private (@SteveEasterbrk and @ petecashmore) and five accounts didn’t publish any content during the studied period (@ andrewmason, @ManpowerGroupJJ, @ MickyArison, @ @NPRGaryKnell, @ rupertmurdoch). Table 1 shows the examined 177 accounts' Twitter handles, numbers of tweets, and numbers of followers (at the time of data collection).

Several organization and leadership accounts listed in Table 1-@ADMupdates, @ Aetna, @AmirRubin,@aneelb,@bgrey, @bjurgs, @bkrunner, @BruceDBroussard, @cjpedregal, @ davidkarp, @DowDuPontCo, @drewhouston, @EIFoundation, @eldsjal, @etaibeck, @Ford, @IndraNooyi, @jasonaramburu, @JeffBezos, @jeremys, @JonasPrising, @ KentThiry, @Louel, @ marissamayer, @merongribetz, @MichelleRhee, @mtbarra, @mtbert, @ peretti, @Phillips66Co, @ ramiessaid, @RobertIger, @ satyanadella, @ seanduffy, @ shervin, @SteveCollis_ABC, @SYFMKeane, @ valgui1, and @WesternUnionCEO - were removed before the final data analysis for better fixed-effect model performance due to their small numbers of tweets published in the studied period $(<100$ tweets).

Two organizations and one leadership account — @ ACLU, @MetLife, and @briansolis _ were also removed due to their early access to the 280 character limit before November 7, 2017, detailed in Section 1.2. Therefore, the final data set used for data analysis $(N=143,771)$ consists of 77,521 tweets from 92 organizations and 66,250 tweets from 43 leadership accounts.

\subsection{Determine the Cutoff Time of Character Limit Change}

To have a rigorous estimation of the appropriate cutoff time for the current study, Figure 1 is plotted, with $\mathrm{X}$ axis indicating the relative publishing time of the tweet and $\mathrm{Y}$ axis indicating the number of characters used by a tweet. Each dot corresponds to a tweet in the data set, while colors indicate different Twitter accounts. It should be noted that the goal is to determine a valid cutoff moment for the current study, instead of the exact moment Twitter switched its character limit from 140 to 280 on its server. The actual server time should be earlier than what the current study suggests.

Panel A shows that two organizations and one leadership accounts - @ ACLU, @ MetLife, and @ briansolis — had early access to the 280 character limit beta-tested since September 2017 (Rosen, 2017). These accounts were thus removed from the main study and Panel B. Panel B shows a closer look at the tweets published 500000 seconds before and after November 7 2017, 00:00:00 GMT, which shows that the first tweet that used more than 140 characters was published by @dickc at November 7 2017, 22:17:17 GMT: https://twitter.com/dickc/ status/928023577416237056

The cutoff time was thus determined as November 7 2017, 22:17:16 GMT. 
Table 1: Data Description (N=177)

\begin{tabular}{|c|c|c|c|c|c|c|c|c|}
\hline Twitter Handles & No. of Followers & No. of Tweets & Twitter Handles & No. of Followers & No. of Tweets & Twitter Handles & No. of Followers & No. of Tweets \\
\hline ACLU & 1594861 & 4130 & etaibeck & 344 & 55 & mtbert & 16478 & 8 \\
\hline ADMupdates & 4586 & 44 & ExpressScripts & 22211 & 380 & nature_org & 929635 & 1881 \\
\hline Aetna & 50551 & 65 & exxonmobil & 299785 & 326 & nyphospital & 38414 & 2369 \\
\hline Albertsons & 29477 & 121 & FannieMae & 50297 & 737 & operationbless & 590672 & 1435 \\
\hline amazon & 2985035 & 649 & FedEx & 276632 & 386 & PAN_Foundation & 4438 & 161 \\
\hline American_Heart & 267899 & 2183 & FeedingAmerica & 459658 & 726 & pepsi & 3010565 & 303 \\
\hline AmericanCancer & 1148001 & 372 & feedthechildren & 22069 & 367 & peretti & 78970 & 44 \\
\hline Americares & 71657 & 2524 & FoodForThePoor & 95007 & 918 & PeterAceto & 29961 & 675 \\
\hline AmFamJack & 11793 & 1326 & Ford & 1169614 & 79 & Phillips66Co & 8776 & 66 \\
\hline AmirRubin & 555 & 2 & FreddieMac & 68383 & 451 & PPFA & 261874 & 703 \\
\hline AndrewGrill & 18060 & 957 & garyvee & 2204334 & 4487 & ProcterGamble & 199284 & 428 \\
\hline aneelb & 23076 & 10 & generalelectric & 455686 & 362 & Prudential & 153346 & 419 \\
\hline AnthemInc & 34693 & 379 & GM & 687677 & 409 & PSIimpact & 38237 & 1051 \\
\hline ashoddd & 729 & 110 & Good360 & 16021 & 534 & ramiessaid & 3281 & 31 \\
\hline ATT & 870301 & 512 & GoodwillIntl & 31784 & 244 & realDonaldTrump & 86432161 & 2274 \\
\hline BankofAmerica & 521966 & 252 & Google & 21010574 & 967 & RedCross & 5338339 & 447 \\
\hline Benioff & 1035726 & 901 & Habitat_org & 1082053 & 703 & richardbranson & 12621404 & 3461 \\
\hline BGCA_Clubs & 44303 & 425 & Healthcare_ABC & 4121 & 471 & RobertIger & 211378 & 45 \\
\hline bgrey & 1298 & 66 & HealthWellOrg & 1805 & 245 & RomanStanek & 12318 & 232 \\
\hline bhalligan & 77727 & 275 & HomeDepot & 380907 & 305 & Rotary & 328152 & 1278 \\
\hline Bill_Gross & 244365 & 448 & IBM & 520978 & 917 & rwang0 & 128758 & 10044 \\
\hline BillGates & 52078446 & 294 & IndraNooyi & 84908 & 40 & SalvationArmyUS & 65094 & 471 \\
\hline bjurgs & 611 & 56 & intel & 4794263 & 500 & SamaritansPurse & 1021785 & 1566 \\
\hline bkrunner & 18582 & 86 & invoker & 51960 & 253 & SameerPatel & 14267 & 548 \\
\hline Boeing & 527532 & 231 & jack & 4786406 & 368 & satyanadella & 2320844 & 76 \\
\hline briansolis & 280067 & 2055 & jasonaramburu & 2034 & 1 & SavetheChildren & 2849455 & 1518 \\
\hline BruceDBroussard & 6358 & 18 & JeffBezos & 1716318 & 58 & SchambachSays & 1880 & 119 \\
\hline bryankramer & 191227 & 3144 & jeffweiner & 602673 & 156 & seanduffy & 4918 & 7 \\
\hline cardinalhealth & 14757 & 380 & jeremys & 215911 & 71 & shervin & 98904 & 82 \\
\hline CARE & 1275433 & 571 & JNJCares & 101792 & 1007 & shrinershosp & 21666 & 1564 \\
\hline CarterCenter & 67814 & 1040 & Jon_Ferrara & 26862 & 3986 & sloan_kettering & 68548 & 1514 \\
\hline CatholicRelief & 75711 & 2081 & JonasPrising & 7471 & 52 & StateFarm & 99881 & 181 \\
\hline CCharitiesUSA & 33416 & 657 & JoSchneier & 986 & 130 & StepUp4Students & 2661 & 648 \\
\hline CEOMikeJackson & 15015 & 125 & KentThiry & 3415 & 88 & SteveCase & 735655 & 1415 \\
\hline charleneli & 104961 & 109 & kevinrose & 1591406 & 175 & SteveCollis_ABC & 456 & 13 \\
\hline Chase & 364661 & 427 & KidneyFund & 14659 & 941 & SteveForbesCEO & 231577 & 1894 \\
\hline Chevron & 358449 & 213 & kroger & 144616 & 384 & StJude & 436179 & 378 \\
\hline chrisbrogan & 334108 & 4942 & LadyAshBorg & 13196 & 257 & SYFMKeane & 2142 & 7 \\
\hline ChuckRobbins & 54734 & 234 & levie & 2422903 & 134 & Target & 1934264 & 228 \\
\hline Citi & 912235 & 1253 & Louel & 1251 & 7 & TFGH & 2644 & 170 \\
\hline cjpedregal & 466 & 10 & Lowes & 267178 & 693 & TheJDC & 13875 & 132 \\
\hline CMMBTweets & 23730 & 777 & LutheranSvcs & 945 & 454 & tim_cook & 12179895 & 184 \\
\hline comcast & 175114 & 200 & MakeAWish & 220355 & 2150 & timoreilly & 1764546 & 833 \\
\hline compassion & 213258 & 878 & mapintl & 2756 & 396 & UNICEFUSA & 422709 & 2560 \\
\hline crutweets & 16762 & 1862 & MarathonPetroCo & 6095 & 197 & UnitedHealthGrp & 16742 & 252 \\
\hline CVSHealth & 44518 & 1182 & marissamayer & 1601132 & 11 & UnitedWay & 199821 & 937 \\
\hline DanaFarber & 88496 & 1793 & markfidelman & 85474 & 17495 & UPS & 208939 & 470 \\
\hline DanReich & 2404 & 112 & MarkVHurd & 154731 & 127 & UTC & 41725 & 315 \\
\hline davemorin & 416940 & 267 & MayoClinic & 1900162 & 4696 & ValeroEnergy & 7536 & 198 \\
\hline davidkarp & 38579 & 43 & McKesson & 19906 & 1019 & valguil & 266 & 36 \\
\hline Dell & 709133 & 900 & mcuban & 7977564 & 151 & verizon & 1662368 & 332 \\
\hline dens & 84417 & 1786 & merongribetz & 2451 & 13 & Walgreens & 885004 & 226 \\
\hline dickc & 1562103 & 144 & MetLife & 53173 & 302 & Walmart & 965347 & 663 \\
\hline DirectRelief & 90435 & 403 & MichaelDell & 657257 & 280 & WellsFargo & 304561 & 234 \\
\hline DowDuPontCo & 4278 & 31 & MichelleRhee & 73765 & 10 & WendySLea & 10356 & 839 \\
\hline drewhouston & 280373 & 13 & Microsoft & 8553405 & 587 & WesternUnionCEO & 15150 & 57 \\
\hline EIFoundation & 2312 & 22 & MountSinaiNYC & 72237 & 4754 & WorldVision & 1157165 & 1308 \\
\hline eldsjal & 146048 & 29 & MSF_USA & 901557 & 846 & ymca & 38763 & 744 \\
\hline elonmusk & 39040874 & 340 & mtbarra & 52225 & 70 & ytechdata & 1463 & 219 \\
\hline
\end{tabular}

\subsection{Variables}

The numbers of characters, URLs, media, hashtags, and mentions were provided by Twitter API. Internal URLs (i.e., retweet with comments by quoting tweets as URLs) do not contribute to the tweet's character count. Characters needed to hyperlink media content also do not count toward a tweet's character allowance. For example, before the character limit change, users were allowed to post a tweet with 140 text characters along with an image.

Considering the fact that external URLs take up large numbers of characters that do not 
convey any textual meaning, the number of text characters was created as the number of total characters minus the number of characters taken by external URLs. Users' external URLs are shortened by Twitter's in-house URL shortener to 23 character per item when posted on the platform.

Therefore, in the main text, the number of text characters (Text) refers to the number of characters used by textual information, including plain text, hashtags, and mentions. The numeric variable is obtained by subtracting the number of characters used by external URLs from the total number of characters.

\section{References}

Afshar, V. (2013). The top 50 social chief executive officers (CEOs) on Twitter. HuffPost. Retrieved from https://www.huffpost.com/entry/the-top-50-social-chief-e_b $-3380055$

Rosen, A. (2017). Tweeting made easier. Retrieved from https://blog.twitter.com/ official/en_us/topics/product/2017/tweetingmadeeasier.html

Yue, C. A., Thelen, P., Robinson, K., \& Men, L. R. (2019). How do CEOs communicate on Twitter? A comparative study between Fortune 200 companies and top startup companies. Corporate Communications: An International Journal, 24(3), 532-552.

Figure 1: Determine Cutoff Time
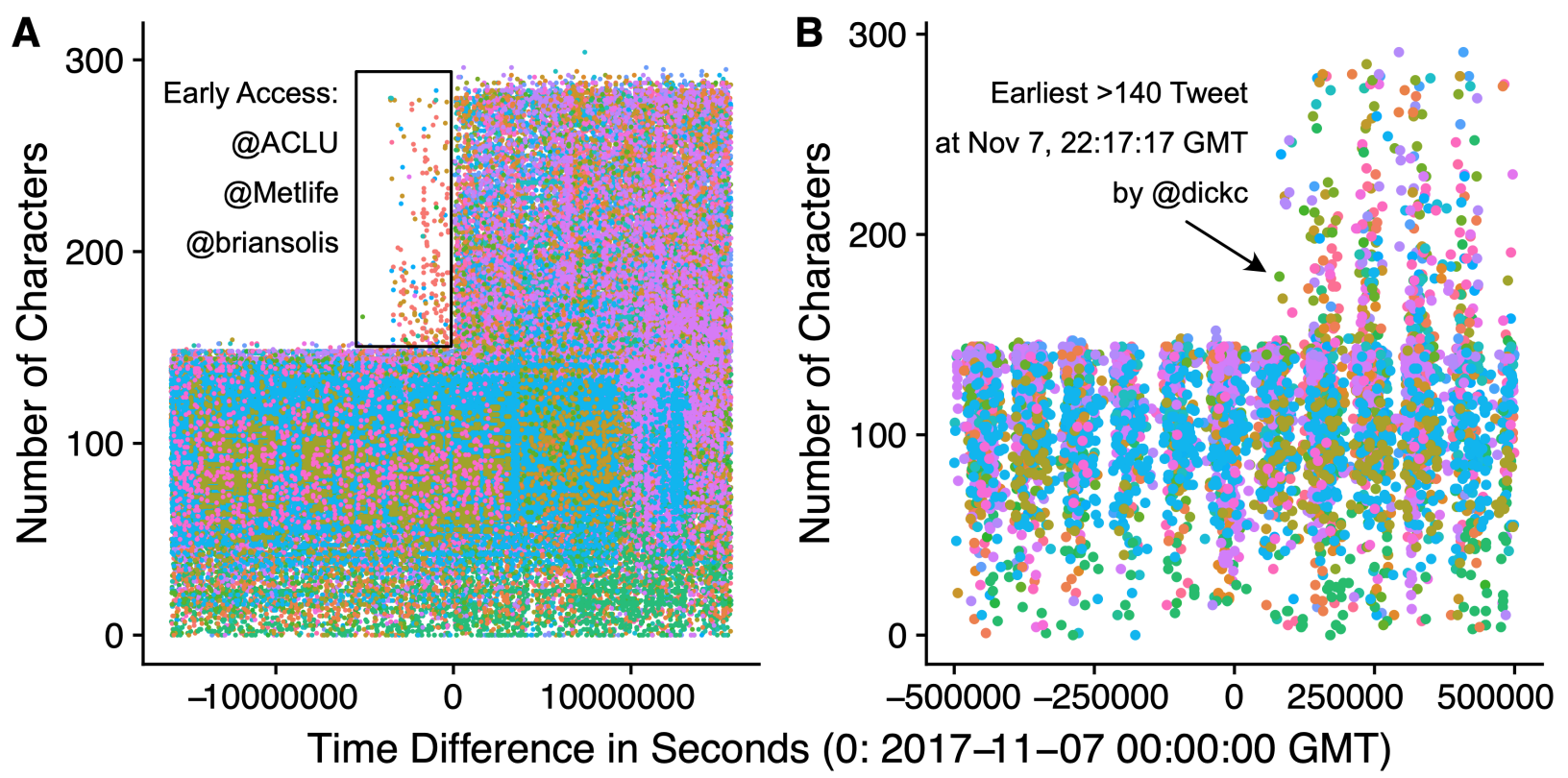
Figure 2: Differential Treatment Effects $\left(\beta_{4}\right)$ of Affordance Change on Number of Characters

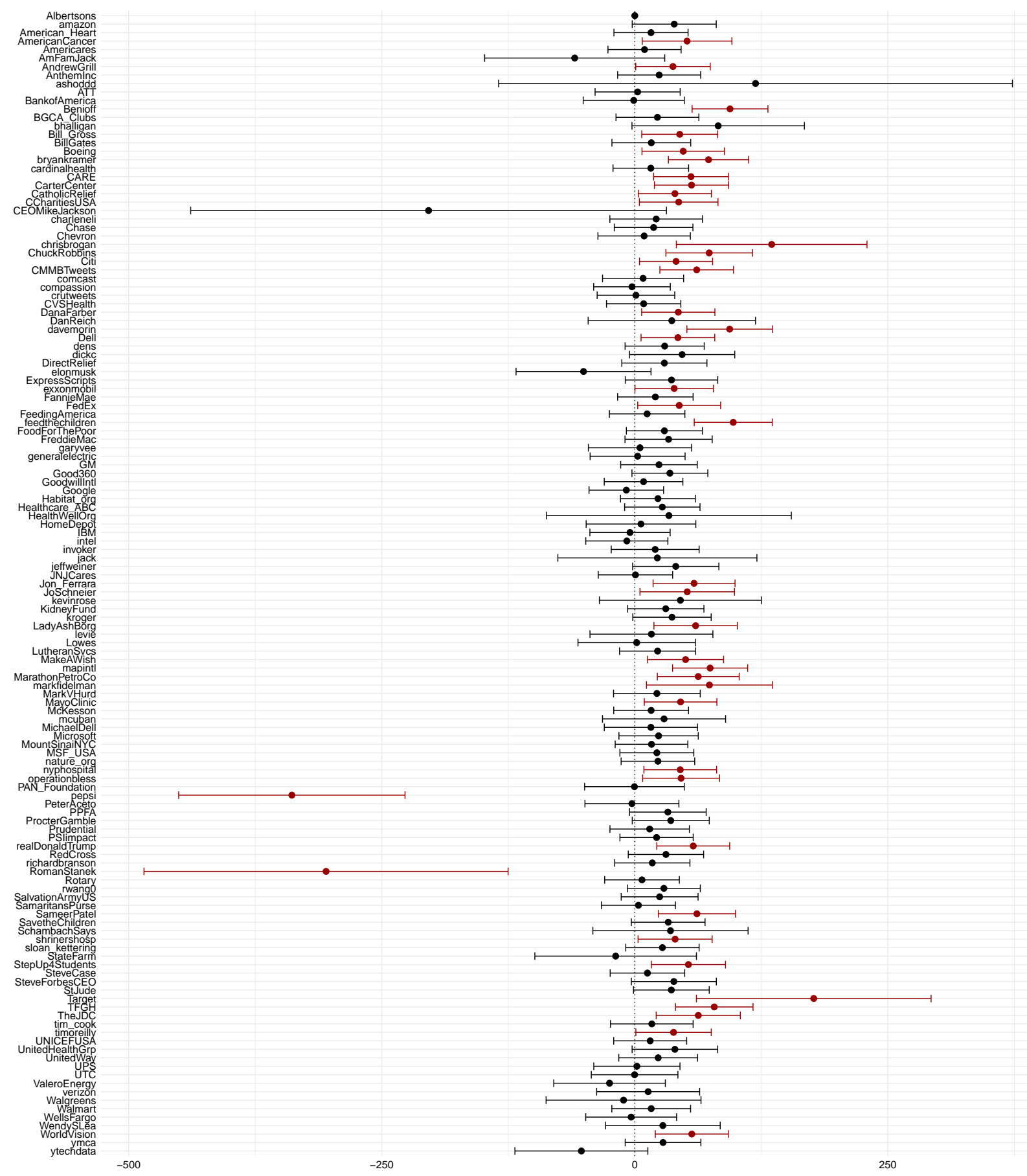

Note: Despite population-level changes, the effect of affordance change on examined Twitter accounts' communication behavior still varies. Shown in the figure is the estimates of the interaction coefficients $\left(\beta_{4}\right)$ for the use of total characters. @ Albertsons is the reference level. Red indicates statistical significance at the 0.05 level. 
Figure 3: Differential Treatment Effects $\left(\beta_{4}\right)$ of Affordance Change on Number of Media

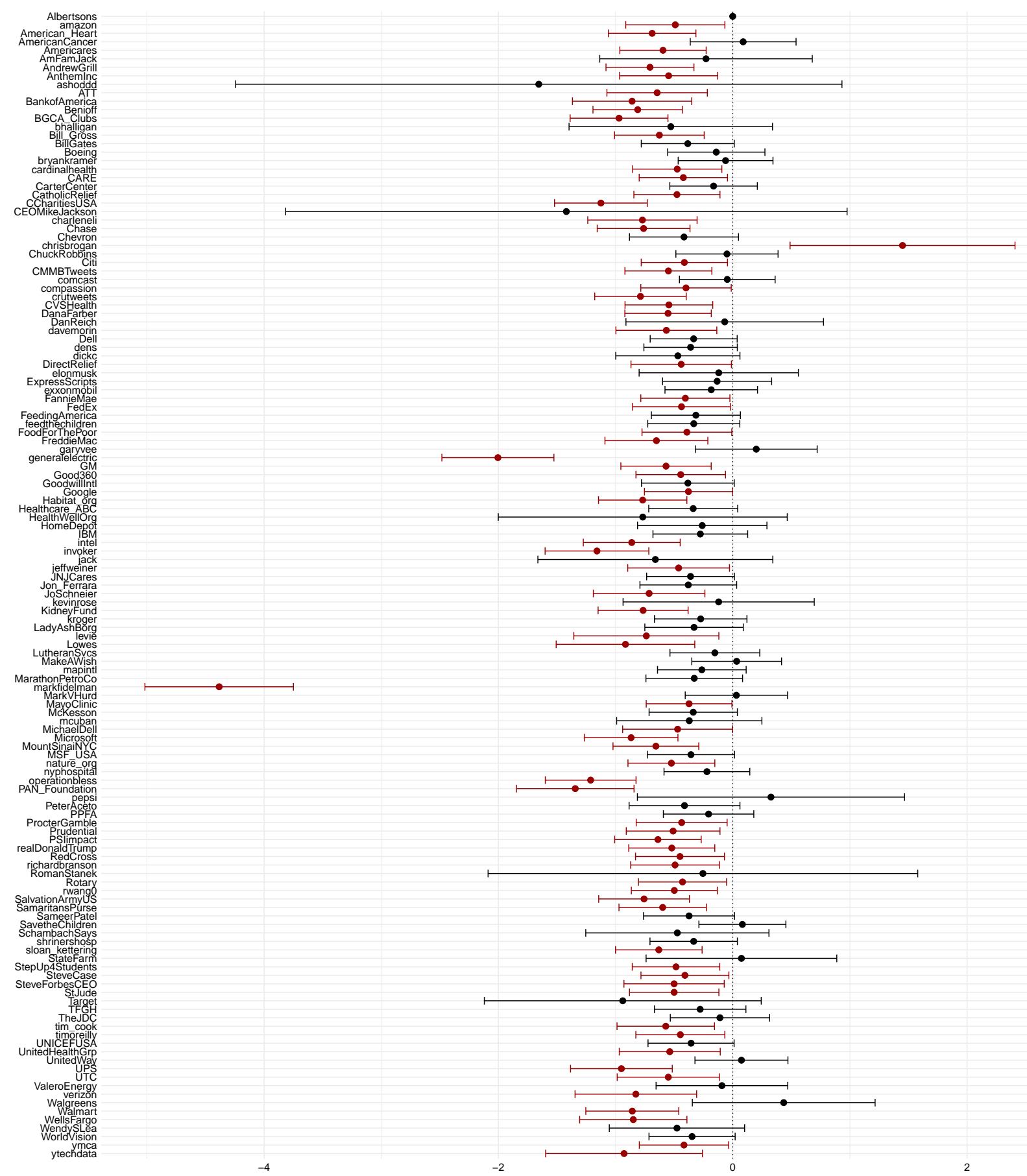

Note: Despite population-level changes, the effect of affordance change on examined Twitter accounts' communication behavior still varies. Shown in the figure is the estimates of the interaction coefficients $\left(\beta_{4}\right)$ for the use of media. @ Albertsons is the reference level. Red indicates statistical significance at the 0.05 level. 
Table 2: Regression Results on Between-Subject Variances of Feature Use

\begin{tabular}{|c|c|c|c|c|c|c|c|c|c|c|c|c|c|c|}
\hline & \multicolumn{14}{|c|}{ Interaction Coefficient $\beta_{4}$} \\
\hline & Charact & & Text & & Mentic & & Hasht & & UR & & $\mathrm{Mec}$ & & Featı & \\
\hline User Engagement Level & $\begin{array}{l}10,435.280^{*} \\
(6,073.917)\end{array}$ & & $\begin{array}{c}-115.798 \\
(5,958.531)\end{array}$ & & $\begin{array}{c}-552.478^{* * *} \\
(63.740)\end{array}$ & & $\begin{array}{c}-1.996 \\
(108.298)\end{array}$ & & $\begin{array}{c}544.449^{* * *} \\
(83.095)\end{array}$ & & $\begin{array}{l}-85.706 \\
(55.028)\end{array}$ & & $\begin{array}{c}-95.731 \\
(151.737)\end{array}$ & \\
\hline Communication Constraint & & $\begin{array}{l}-0.070 \\
(0.247) \\
\end{array}$ & & $\begin{array}{c}0.126 \\
(0.239) \\
\end{array}$ & & $\begin{array}{c}0.005 \\
(0.003) \\
\end{array}$ & & $\begin{array}{l}-0.003 \\
(0.004) \\
\end{array}$ & & $\begin{array}{c}-0.008^{* *} \\
(0.004)\end{array}$ & & $\begin{array}{c}-0.0001 \\
(0.002)\end{array}$ & & $\begin{array}{l}-0.006 \\
(0.006)\end{array}$ \\
\hline Observations & 134 & 134 & 134 & 134 & 134 & 134 & 134 & 134 & 134 & 134 & 134 & 134 & 134 & 134 \\
\hline $\mathrm{R}^{2}$ & 0.022 & 0.001 & 0.00000 & 0.002 & 0.363 & 0.020 & 0.00000 & 0.004 & 0.245 & 0.036 & 0.018 & 0.00001 & 0.003 & 0.008 \\
\hline Adjusted $\mathrm{R}^{2}$ & 0.014 & -0.007 & -0.008 & -0.005 & 0.358 & 0.012 & -0.008 & -0.004 & 0.240 & 0.029 & 0.011 & -0.008 & -0.005 & 0.001 \\
\hline Residual Std. Error $(\mathrm{df}=132)$ & 56.424 & 57.035 & 55.352 & 55.295 & 0.592 & 0.734 & 1.006 & 1.004 & 0.772 & 0.872 & 0.511 & 0.516 & 1.410 & 1.406 \\
\hline F Statistic (df = 1; 132) & $2.952^{*}$ & 0.079 & 0.0004 & 0.277 & $75.130^{* * *}$ & 2.642 & 0.0003 & 0.476 & $42.930^{* * *}$ & $4.955^{* *}$ & 2.426 & 0.002 & 0.398 & 1.082 \\
\hline
\end{tabular}

